\title{
SEISMIC ANALYSIS AND THE INFLUENCE OF ZONE FACTOR OF A MULTI STOREY HOSPITAL BUILDING - A CASE STUDY
}

By

\section{K. SUBRAMANIAN *}

* Professor \& Head, Department of Civil Engineering, Coimbatore Institute of Technology, Coimbatore. ** PhD candidate, Anna University of Technology, Coimbatore.

\section{VELAYUTHAM **}

\section{ABSTRACT}

Earthquake on $26^{\text {th }}$ January 2001 in Gujarat clearly demonstrated the earthquake vulnerability of India. Almost more than $60 \%$ of our land is vulnerable to earthquake of magnitude more than 7 . This leads to the professionals to carry out the research on seismic forces that influence on the structures. This paper presents a detailed case study of an upcoming Ten Storey Hospital building analyzed in ETABS using Response Spectrum analysis of IS 1893 (Part1):2002. The proposed structural system for the hospital building consists of conventional beam, column and slab system with lift walls and walls around staircase acting as shear wall. Lateral Stability is provided by shear walls and columns. The upcoming building is proposed to construct in the Zone III region. Importance factor of 1.5 is considered for the structure considering its functionality. The case study discuss on the influence of various zone factors and the codal provisions, when the same building to be located in different regions. Ductile systems are taken in the study, where inelastic analysis procedures effectively accountfor several sources of force reduction.

The earthquake ground acceleration in each direction is given as a digitized response-spectrum curve of pseudospectral acceleration response versus period of the structure. The peak response quantities such as member forces, displacements, storey forces, storey shears and base reactions shall be combined as per Complete Quadratic Combination method. The accidental eccentricity is given as direct input in all floor diaphragms. The dynamic analysis results such as modal participating mass ratios, response spectrum base reaction, storey shears, storey displacements and storey drifts are discussed in detail. Animated results of the displacement due to all modes along with their respective time period are displayed for more understanding of the structural behavior. First and Second modes are found to be in translation and third mode is of torsional mode, which is an acceptable solution to proceed with detailed design.

Keywords: Case Study, Seismic Analysis, Zone Factors, Response Spectrum, Time Period And Mode Shapes.

\section{INTRODUCTION}

Earthquake on $26^{\text {th }}$ January 2001 (Republic Day) in Gujarat clearly demonstrated the earthquake vulnerability of India. Almost more than $60 \%$ of our land is vulnerable to earthquake of magnitude more than 7. This leads to the professionals to carry out the research on seismic forces that influence on the structures.

The behavior of a building during earthquakes depends critically on its overall shape, size and geometry, in addition to how the earthquake forces are carried to the ground. For the proposed hospital building, the lateral load resisting members such as shear walls and columns are placed in a position such that the overall mass of the building coincides with the rigidity of lateral load resisting member as far as possible to avoid the torsion in the building during initial modes.

Many years of development of world-class computer applications for analysis and design of structures that have changed and modernized structural engineering practice to a level never envisioned just a few decades ago. ETABS is the product of Computers and Structures, Inc. one of such kind which is very efficient and usable structural analysis program for various Structural Engineering problems. ETABS will automatically generate seismic loads based on various domestic and international codes. Efficient in creating three 
dimensional mode shapes and frequencies, modal participation factors, direction factors and participating mass percentages are evaluated using eigenvector or ritz-vector analysis.

This paper deals with a case study of upcoming ten storey hospital building analyzed in ETABS using response spectrum analysis as per IS 1893 (Part 1):2002.

\section{Literature Review}

In order to access and to critically evaluate the research work done on the seismic analysis of multistory buildings and computer aided dynamic analysis, a detailed review of literature has been undertaken and few of them are listed below.

Shahram Taghavi et al (2008) studied response spectrum method to estimate peak floor acceleration demands of multi storey buildings subjected to earthquakes and suggested empirical equations. Behavior of reinforced concrete structures with shear wall and infill for seismic forces was studied by Shahabodin.Zaregarizi (2008) and suggested as combination of concrete and brick infill is very effective in resisting the earthquake forces. Thomas Paulay (1983) has given brief review of a deterministic design philosophy with respect to earthquake resisting ductile structures for reinforced concrete buildings and highlighted the capacity design procedures relevant to beams, columns and shear walls. Proper selection of the load carrying system for better performance during earthquake was studied by Moehle at al (1991) and highlighted the redistribution of internal forces in the event of disproportionate collapse. Hyun-Su Kima et al (2005) studied the reinforced concrete walls and slabs for earthquake resistance of a high-rise building and proposed a refined finite element model for an accurate analysis of shear wall with service openings.

\section{Problem Reported}

The case study is taken on the upcoming building of a ten storey structure used for hospital functionalities. The base dimensions of the building are $29 \times 26.4 \mathrm{~m}$ and the total height of building is $49.25 \mathrm{~m}$. The proposed structural system for the hospital building consists of conventional beam, column and slab system with lift walls and walls around staircase. The structural plan of the first floor is shown in Figure 1 and the dimensions of the structural members are given in Table 1 .

\section{Methodology}

Buildings with regular, or nominally irregular plan configuration may be modeled as a system of masses lumped at floor levels with each mass having one degree of freedom, that of lateral displacement in the direction under consideration.

Undamped free vibration analysis of entire building modeled as spring - mass model shall be performed using appropriate masses and elastic stiffness of the structural system to obtain natural periods (T) and mode shapes $\{\varphi\}$ of those of its modes of vibration that needs to be considered. The number of modes to be used should be such that the sum of total of modal masses of all modes considered is at least $90 \%$ of total seismic mass.

In dynamic analysis the following expressions shall be used for the computation of various quantities:

\subsection{Modal mass $\left(\mathrm{M}_{\mathrm{k}}\right)$}

Modal mass of the structure subjected to horizontal or vertical as the case may be, ground motion is a part of the total seismic mass of the structure that is effective in mode $\mathrm{k}$ of vibration. The modal mass for a given mode has a unique value, irrespective of scaling of the mode shape.

$$
\mathrm{M}_{\mathrm{k}}=\left(\Sigma \mathrm{W}_{\mathrm{i}} \varphi_{\mathrm{ik}}\right)^{2} /\left(\mathrm{g} \Sigma \mathrm{W}_{\mathrm{i}} \varphi_{\mathrm{ik}}{ }^{2}\right)
$$

\subsection{Modal Participation Factor $\left(\mathrm{P}_{\mathrm{k}}\right)$}

Modal participation factor of mode $k$ of vibration is the amount by which mode k contributes to the overall vibration of the structure under horizontal or vertical earthquake ground motions. Since the amplitudes of 95 percent mode shape can be scaled arbitrarily, the value of this factor depends on the scaling used for the mode shape.

$$
\mathrm{P}_{\mathrm{k}}=\left(\Sigma \mathrm{W}_{\mathrm{i}} \varphi \mathrm{ik}\right) /\left(\Sigma \mathrm{W}_{\mathrm{i}} \varphi_{\mathrm{ik}}{ }^{2}\right)
$$

\subsection{Design lateral force at each floor in each mode (Qik)}

The peak lateral force (Qik) at floor i in mode $k$ is given by

\begin{tabular}{cc}
\hline Members & Sizes $(\mathrm{mm})$ \\
\hline Columns & $400 \times 600,400 \times 800,400 \times 1150,200 \times 500,600$ Dia \\
Walls & 200 Thick \\
Beams & $400 \times 450,400 \times 600,200 \times 450,200 \times 600$ \\
Slabs & 115 Thick \\
\hline
\end{tabular}

Table 1. Members Dimensions of the Upcoming Hospital Building 


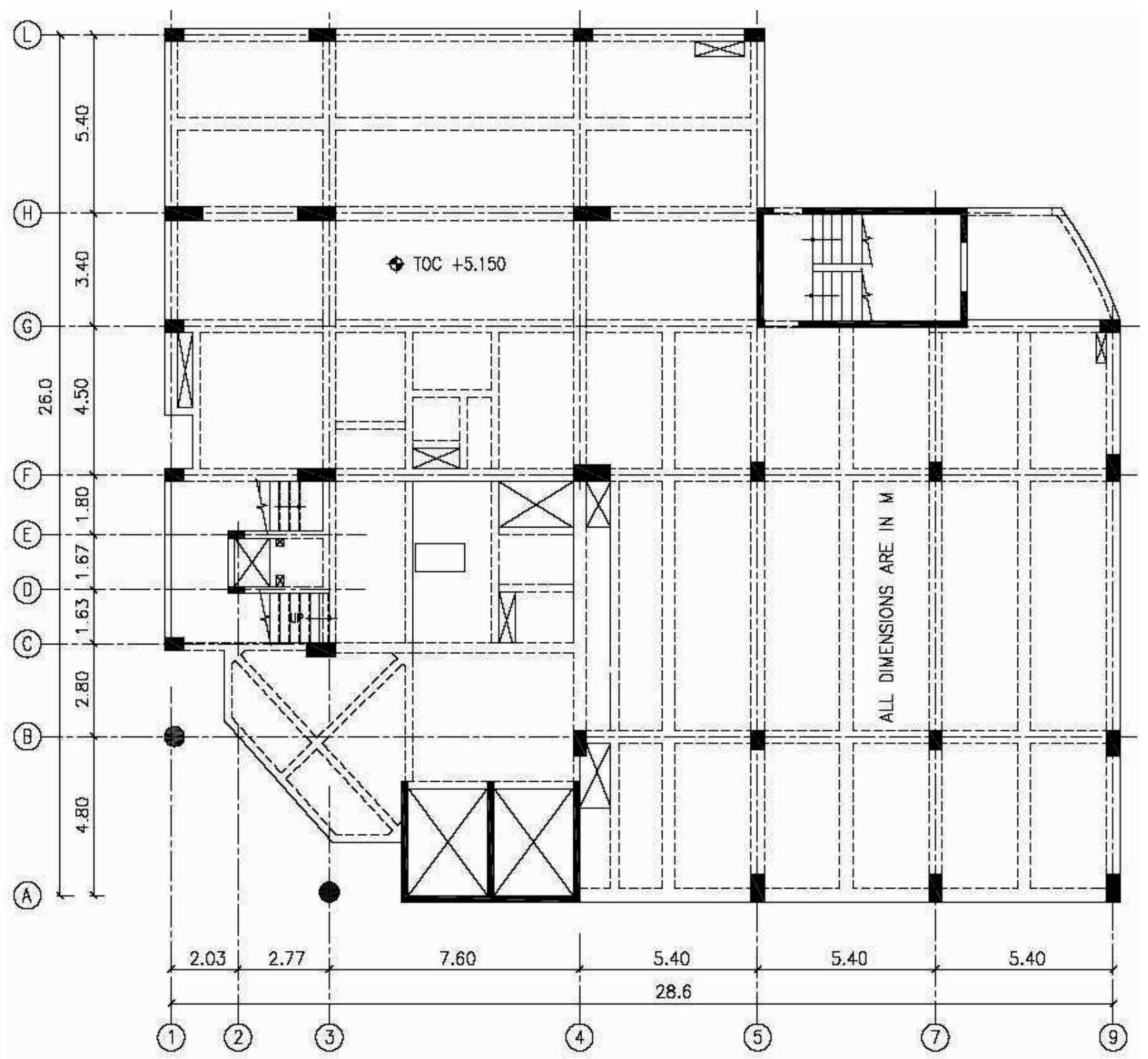

Figure 1. Structural plan of the upcoming hospital building

$$
\text { Qik }=\text { Ak } \varphi \text { ikPkWi }
$$

Where,

$$
A k=(Z / 2 * 1 / R * S a / g)
$$

\subsection{Storey Shear Forces in Each Mode}

The peak shear force $\left(\mathrm{V}_{\mathrm{ik}}\right)$ acting in storey $\mathrm{i}$ in mode $\mathrm{k}$ is given by

$$
\mathrm{V}_{\mathrm{ik}}=\Sigma Q_{\mathrm{ik}}
$$

\subsection{Storey shear force due to all modes considered}

The peak storey shear force (Vi) in storey i due to all modes considered is obtained by combining those due to each mode as per following rules:

\subsubsection{CQCMethod}

The peak response quantities shall be combined as per Complete Quadratic Combination (CQC) method

where,

$$
\lambda=\sqrt{\begin{array}{cc}
\mathrm{r} & \mathrm{r} \\
\sum_{1} & \sum \lambda \mathrm{i} \rho \mathrm{ij} \lambda \mathrm{j}
\end{array}}
$$

$$
\rho i j=\frac{8 \zeta^{2}(1+\beta) \beta^{1.5}}{\left(1-\beta^{2}\right)^{2}+4 \zeta^{2} \beta(1+\beta)^{2}}
$$

\subsubsection{SRSS Method}

If the building does not have closely spaced modes, than 
the peak response quantity $(\lambda)$ due to all modes considered shall be obtained as per Square Root of Sum of Square method

$$
\lambda=\sqrt{\sum_{1}^{r} \Sigma\left(\lambda_{k}\right)^{2}}
$$

If the building has a few closely spaced modes, then the peak response quantity $\left(\lambda^{\star}\right)$ due to these modes shall be obtained as

$$
\lambda^{*}=\underset{\substack{\mathrm{r} \\ \mathrm{c}}}{\left.\mathrm{c} \lambda_{\mathrm{k}}\right)}
$$

Where the summation is for the closely spaced modes only. This peak response quantity due to the closely spaced modes $\left(\lambda^{*}\right)$ is then combined with those of the remaining well separated modes by the method of SRSS.

\subsection{The Design Base Shear $\left(\mathrm{V}_{\mathrm{B}}\right)$}

The design base shear $\mathrm{V}_{\mathrm{B}}$ from the dynamic analysis shall be compared with base shear $V_{B}$ calculated using a fundamental period Ta, as given by empirical formula of clause 7.6 of IS 1893. Where $V_{B}$ is less than $V_{B}$, all the response quantities shall be multiplied by $V_{B} / V_{B}$.

\section{Analysis Results}

The seismic analysis is performed using ETABS as per the response spectrum analysis of IS 1893 (Part 1):2002. Analytical model of a ten storey hospital is shown in Figure 2. Time period of the structure and modal participating mass ratios are displayed in Table 2 . It is found that the first and second mode is in translation mode. First mode is in $Y$ direction translation and excites $65.26 \%$ of the total mass.

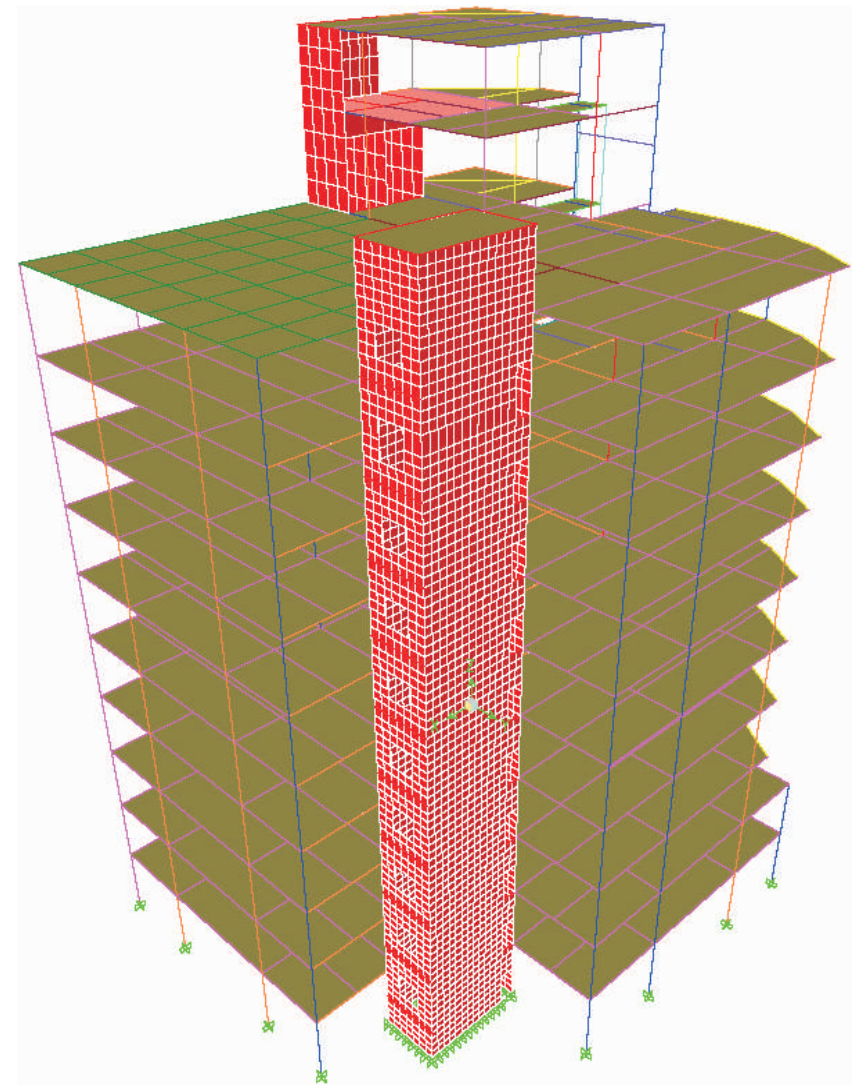

Figure 2. Analytical Model of a Ten Storey Hospital Building

Second mode is of $X$ direction translation and excites $67.71 \%$ of the total mass. It is seen that 8 th and 10 th modes satisfied with more than $90 \%$ of total mass participated by acceleration in $\mathrm{Y}$ and $\mathrm{X}$ direction respectively.

As per clause 7.8.2 of IS 1893 the design base shear $V_{B}$ shall be compared with base shear $\mathrm{V}_{\mathrm{B}}$ calculated using a

\begin{tabular}{|c|c|c|c|c|c|c|c|}
\hline Mode & Period & $\begin{array}{l}\% \text { of mass participated in } \\
X \text { direction acceleration }\end{array}$ & $\begin{array}{l}\% \text { of mass participated in } \\
\text { Y direction acceleration }\end{array}$ & $\begin{array}{l}\% \text { of mass participated in } \\
Z \text { direction acceleration }\end{array}$ & $\begin{array}{l}\text { Sum of } \% \text { mass } \\
\text { in } X \text { dir. }\end{array}$ & $\begin{array}{l}\text { Sum of } \% \text { mass } \\
\text { in } Y \text { dir. }\end{array}$ & $\begin{array}{l}\text { Sum of \% mass } \\
\text { in Z dir. }\end{array}$ \\
\hline 1 & 1.98 & 0.15 & 65.26 & 0.00 & 0.15 & 65.26 & 0.00 \\
\hline 2 & 1.48 & 67.71 & 0.13 & 0.00 & 67.86 & 65.39 & 0.00 \\
\hline 3 & 1.19 & 0.00 & 4.16 & 0.00 & 67.87 & 69.56 & 0.00 \\
\hline 4 & 0.54 & 0.00 & 14.17 & 0.01 & 67.87 & 83.73 & 0.01 \\
\hline 5 & 0.41 & 10.56 & 0.14 & 0.00 & 78.43 & 83.87 & 0.01 \\
\hline 8 & 0.25 & 0.89 & 3.93 & 0.43 & 87.64 & 91.04 & 0.53 \\
\hline 9 & 0.19 & 0.21 & 1.65 & 2.91 & 87.85 & 92.70 & 3.44 \\
\hline 10 & 0.15 & 5.67 & 0.04 & 0.52 & 93.52 & 92.74 & 3.96 \\
\hline 11 & 0.12 & 0.10 & 5.82 & 0.42 & 93.62 & 98.55 & 4.37 \\
\hline 12 & 0.08 & 5.45 & 0.04 & 0.38 & 99.07 & 98.59 & 4.75 \\
\hline
\end{tabular}
fundamental period Ta. It is found from ETABS dynamic

Table 2. Time Period and Modal Participating Mass Ratios 
analysis that the design base shears VBx and VBy are $1316.18 \mathrm{kN}$ and $1114.10 \mathrm{kN}$ respectively which is less than $V_{B}$ calculated using a fundamental period Ta explained below, so that all the response quantities such as member forces, displacements, storey forces, storey shear and base reactions shall be multiplied by $\bigvee_{B} / V_{B}$.

The hospital building is medium infill structure and the base shear is calculated by taking the average of with and without infill to match the realistic behavior. Seismic analysis and ductile detailing as per IS 13920 is mandatory for the structure considered for this case study, since the building location is falls under Category of Zone III. Zone factor of 0.16 and the Type $\|$ soil is used considering its locality. Ductility factor of 5 is used considering the system as dual with ductile detailing to shear walls and moment resisting frame, where inelastic analysis procedures effectively accounts for several sources of force reduction. Importance factor of 1.5 is considered for the structure considering its criticality of the function.

The value of damping for the structure is taken as $5 \%$ of the critical for the dynamic analysis of reinforced concrete building. The seismic weight of each floor considered as full dead load plus appropriate amount of imposed load, as specified in the clause 7.3.1 and 7.3.2 of IS 1893 (Part 1): 2002.

Base shear calculation (with infill):

$\mathrm{T}_{\mathrm{ax}}=0.09 \mathrm{~h} / \mathrm{sqr}\left(\mathrm{d}_{\mathrm{x}}\right) \quad$ As per Clause 7.6.2 of IS 1893 (Part 1):2002

$\mathrm{T}_{\mathrm{ay}}=0.09 \mathrm{~h} / \mathrm{sqrt}\left(\mathrm{d}_{\mathrm{y}}\right) \quad$ As per Clause 7.6.2 of IS 1893 (Part 1):2002
For medium soil $(\mathrm{Sa} / \mathrm{g})_{\mathrm{x}}=1.36 / \mathrm{T}_{\mathrm{ax}} \quad$ As per Clause 6.4.5 of IS 1893 (Part 1):2002

Formedium soil $(\mathrm{Sa} / \mathrm{g})_{\mathrm{y}}=1.36 / \mathrm{T}_{\mathrm{ar}}$ As per Clause 6.4.5 of IS 1893 (Part 1):2002

$\mathrm{V}_{\mathrm{B}}=\mathrm{AhW}$ As per Clause 7.5.3 of IS 1893 (Part 1):2002

$W=108169 k N$ As per Clause 7.4 of IS 1893 (Part 1):2002

$A h=(Z / 2 * I / R * S a / g) \quad$ As per Clause 6.4.2 of IS 1893 (Part 1):2002

Base shear $\overline{\mathrm{V}}_{\mathrm{Bx}}=4288.70 \mathrm{kN}$

Base shear $\overline{\mathrm{V}_{\mathrm{By}}}=4088.79 \mathrm{kN}$

Base shear calculation (without infill):

$T_{a}=0.075 h^{0.75}$ for $R C$ frame building As per Clause 7.6.1 of IS 1893 (Part 1):2002

Formedium soil Sa/g $=1.36 / \mathrm{T}_{\mathrm{a}}$ As per Clause 6.4.5 of IS 1893 (Part 1):2002

Base shear $\overline{\mathrm{V}}_{\mathrm{B}}=2531.16 \mathrm{kN}$

Average base shear $\overline{\mathrm{V}}_{\mathrm{Bx}}=4288.69+2531.16=3409.92 \mathrm{kN}$ Average base shear $\overline{\mathrm{V}}_{\mathrm{By}}=4088.79+2531.16=3309.97 \mathrm{kN}$

Base shear from dynamic analysis $\mathrm{V}_{\mathrm{Bx}}=1316.2 \mathrm{kN}$

Base shear from dynamic analysis $\bigvee_{\text {ву }}=1114.2 \mathrm{kN}$

Hence $\bar{V}_{B}>V_{B}$. Hence all the response quantities are scaled up in the ratio of $3409.92 / 1316.2=2.59$ and $3309.97 / 1114.2=2.97$ in the $X$ and $Y$ direction respectively Tables 3 and 4 displays the storey base shear in $X$ and $Y$ direction respectively after amplifying the quantities as per clause 7.8.2 of IS 1893

\begin{tabular}{|c|c|c|c|c|c|c|c|c|}
\hline Story & Load & Location & $P$ & $V_{x}$ & $V_{\mathrm{r}}$ & $T$ & $\mathrm{M}_{\mathrm{x}}$ & $\mathrm{M}_{\mathrm{r}}$ \\
\hline LEVEL 2 & $E Q x$ & Bottom & 8.88 & 296.28 & 106.80 & 2684.25 & 417.96 & 1161.10 \\
\hline LEVEL 1 & $E Q x$ & Bottom & 5.30 & 599.01 & 147.80 & 5456.23 & 1227.97 & 4217.40 \\
\hline TERRACE & $E Q x$ & Bottom & 61.21 & 1116.32 & 119.21 & 13190.47 & 2100.96 & 9215.80 \\
\hline NINTH & $E Q x$ & Bottom & 74.20 & 1582.56 & 143.58 & 20165.21 & 2235.34 & 15089.50 \\
\hline EIGHTH & $E Q x$ & Bottom & 86.59 & 1883.63 & 188.91 & 24139.41 & 2212.46 & 22131.50 \\
\hline SEVENTTH & $E Q x$ & Bottom & 98.48 & 2139.05 & 225.44 & 27236.44 & 2231.52 & 29928.72 \\
\hline SIXTH & $E Q x$ & Bottom & 108.45 & 2407.32 & 238.30 & 30677.03 & 2459.55 & 38408.55 \\
\hline FIFTH & $E Q x$ & Bottom & 114.77 & 2668.69 & 213.78 & 34378.12 & 2871.39 & 47651.26 \\
\hline FOURTH & $E Q x$ & Bottom & 116.33 & 2889.25 & 178.56 & 37781.94 & 3310.83 & 57672.92 \\
\hline THIRD & $E Q x$ & Bottom & 113.40 & 3105.62 & 242.83 & 41238.10 & 3799.71 & 68431.02 \\
\hline SECOND & $E Q x$ & Bottom & 108.94 & 3312.93 & 348.11 & 44608.20 & 4583.12 & 79908.67 \\
\hline FIRST & $E Q x$ & Bottom & 106.58 & 3410.23 & 372.44 & 46619.58 & 5590.62 & 91909.60 \\
\hline
\end{tabular}

Table 3. Storey Shear in $\mathrm{kN}$ due to $E Q_{\mathrm{x}}$ 


\begin{tabular}{|c|c|c|c|c|c|c|c|c|}
\hline Story & Load & Location & $P$ & $\mathrm{~V}_{\mathrm{x}}$ & $V_{Y}$ & $\mathrm{~T}$ & $\mathrm{M}_{\mathrm{x}}$ & $\mathrm{M}_{\mathrm{r}}$ \\
\hline LEVEL 2 & $E Q_{\gamma}$ & Bottom & 5.09 & 83.90 & 306.01 & 2091.55 & 1201.07 & 318.15 \\
\hline LEVEL 1 & $E Q_{y}$ & Bottom & 7.60 & 167.71 & 636.43 & 4502.85 & 4442.63 & 1114.33 \\
\hline TERRACE & $E Q_{Y}$ & Bottom & 94.81 & 167.93 & 1206.04 & 12849.61 & 9942.71 & 1498.65 \\
\hline NINTH & $E Q_{y}$ & Bottom & 116.57 & 197.59 & 1551.46 & 18794.93 & 15933.84 & 2266.17 \\
\hline EIGHTH & $E Q_{y}$ & Bottom & 137.4 & 270.36 & 1710.63 & 22283.43 & 22313.25 & 3292.04 \\
\hline SEVENTTH & $E Q_{y}$ & Bottom & 158.79 & 283.24 & 1831.18 & 24970.41 & 28663.74 & 4383.51 \\
\hline SIXTH & $E Q_{Y}$ & Bottom & 178.60 & 207.87 & 2005.37 & 27890.56 & 34974.94 & 5148.86 \\
\hline FIFTH & $E Q_{y}$ & Bottom & 193.93 & 196.97 & 2246.62 & 31452.98 & 41514.63 & 5359.57 \\
\hline FOURTH & $E Q_{r}$ & Bottom & 202.11 & 289.58 & 2537.64 & 35488.50 & 48660.13 & 5271.21 \\
\hline THIRD & $E Q_{y}$ & Bottom & 201.91 & 324.51 & 2844.80 & 39688.20 & 56781.48 & 5438.21 \\
\hline SECOND & $E Q_{y}$ & Bottom & 197.82 & 355.18 & 3064.27 & 43071.01 & 66025.14 & 6048.24 \\
\hline FIRST & $E Q_{Y}$ & Bottom & 191.25 & 528.38 & 3310.00 & 48365.58 & 76255.50 & 6388.97 \\
\hline
\end{tabular}

Table 4. Storey Shear in $\mathrm{kN}$ due to $\mathrm{EQ}_{\mathrm{Y}}$

As per Table 7 of IS 1893 (Part1): 2002, the moment resisting frames are designed to independently resist at least 25 percent of the design seismic base shear for dual systems. It is found that the column attracts $10.8 \%$ and $15.6 \%$ of shear in $X$ and $Y$ direction, where these values are less than $25 \%$ of design seismic base shear. The columns are designed for 2.3 and 1.6 times more force than actual in $X$ and $Y$ direction respectively to satisfy the codal provisions.

Figure 3 displays the Storey Vs displacement due to spectral $X$ and $Y$ direction force. The storey drifts are found

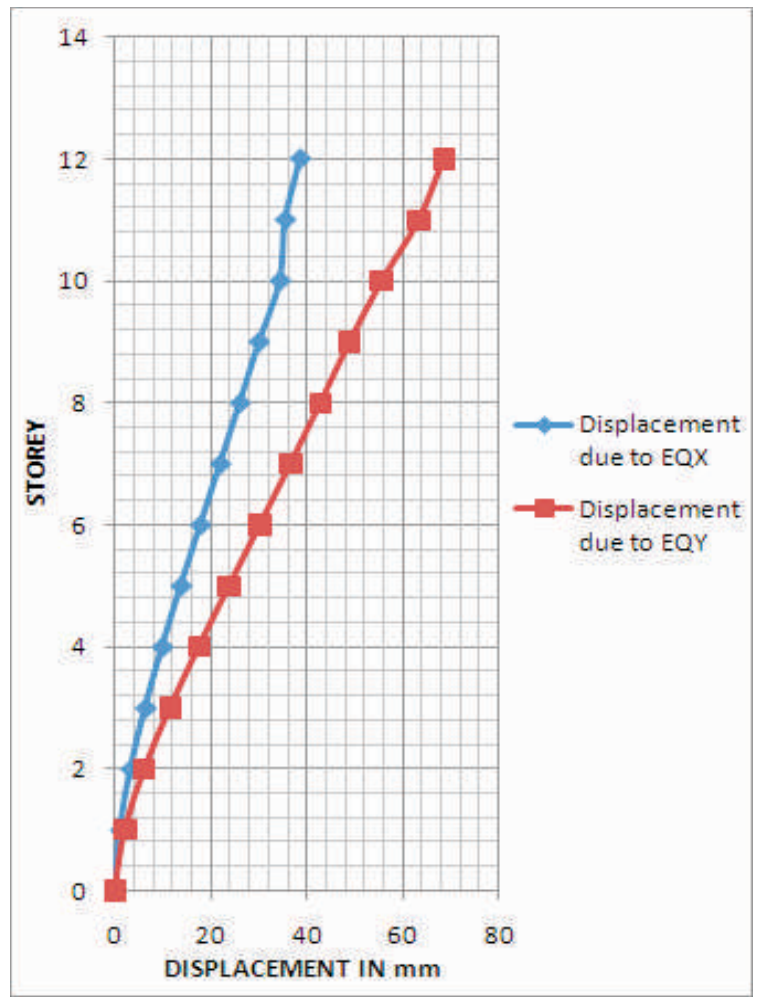

Figure 3. Displacement in $\mathrm{X}$ and $\mathrm{Y}$-Direction to 0.0016 and 0.0022 in $X$ and $Y$ direction respectively. Actual values are well within the limit of 0.004 times the storey height as per clause 7.1 1.1 of IS 1893 (Part1): 2002. Figure 4 displays the Height Vs Storey Shear attracted due to earthquake force in $X$ and $Y$ direction.

The same building is analyzed with various zone factors and the results of the base shears are compared. For the study of influence of zone factors on the structure, apart from the proposed location Zone III, other zones such as Zone IV and $V$ are considered and the results are compared. Table 5 displays the base shear in $X$ and $Y$ direction for the all Zone factors considered. Figure 5 shows the comparison of lateral shear distribution pattern of zones considered as per IS 1893 (Part1): 2002.
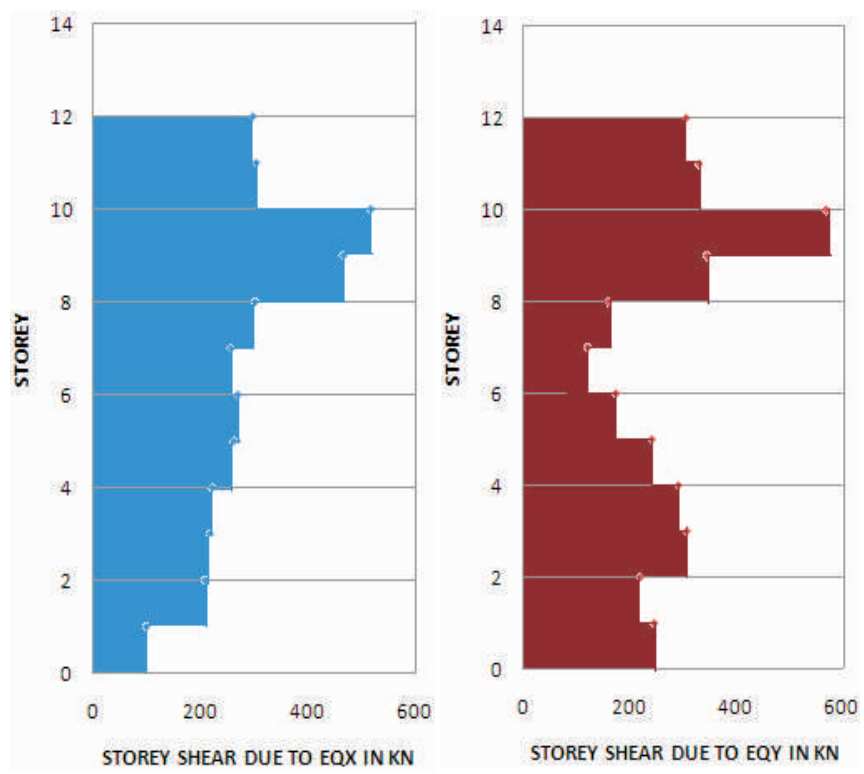

Figure 4. Storey Shear in $X$ and $Y$ Direction 


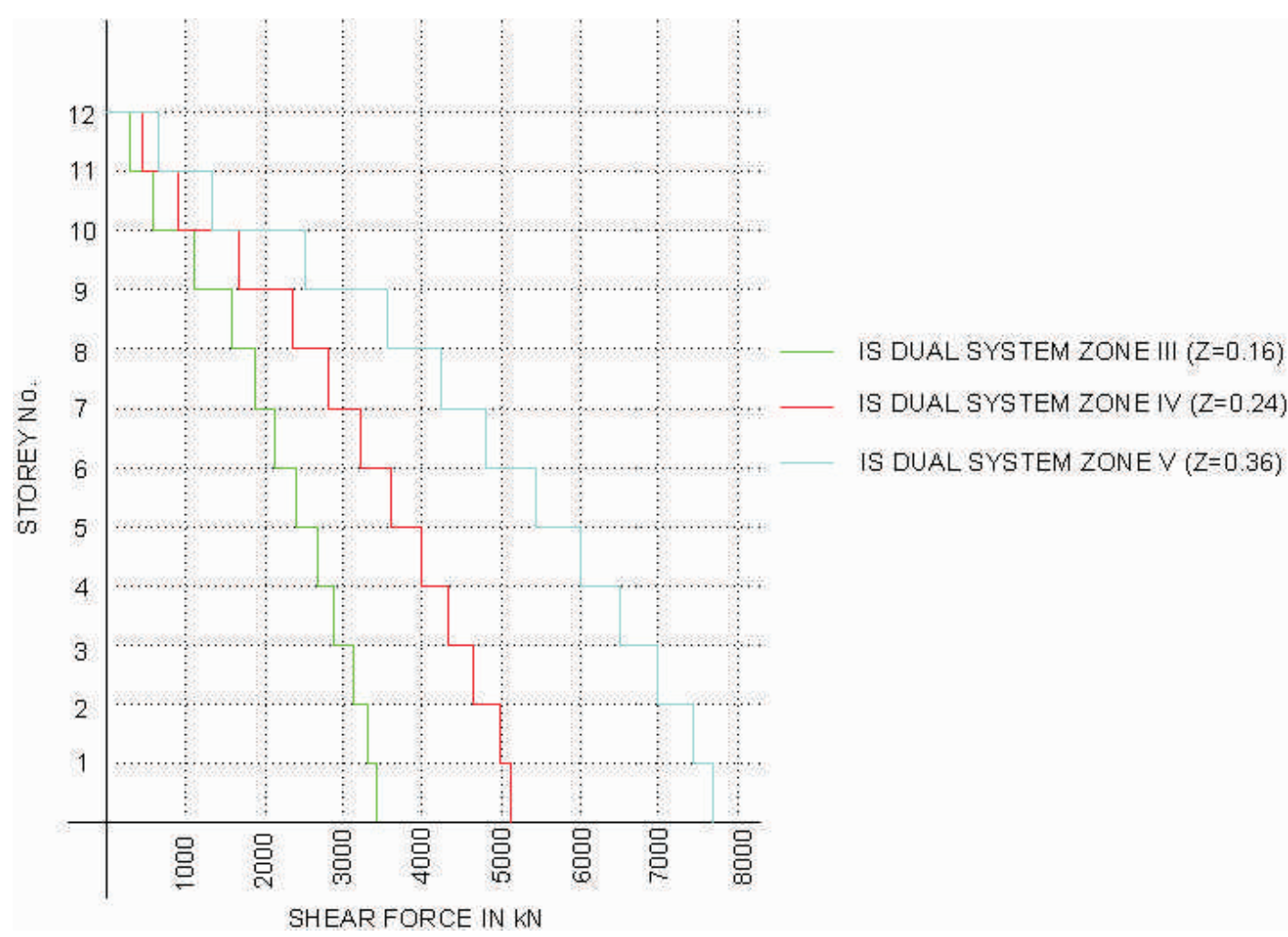

Figure 5. Comparison of Lateral Shear distribution

\begin{tabular}{|c|c|c|c|c|c|c|}
\hline \multirow{2}{*}{ Story } & \multicolumn{2}{|c|}{ ZONE III $(Z=0.16)$} & \multicolumn{2}{|c|}{ ZONE III (Z=0.24) } & \multicolumn{2}{|c|}{ ZONE III $(Z=0.36)$} \\
\hline & $\mathrm{V}_{\mathrm{x}}$ & $\mathrm{V}_{\mathrm{y}}$ & $\mathrm{V}_{\mathrm{x}}$ & $V_{r}$ & $\mathrm{~V}_{\mathrm{x}}$ & $V_{y}$ \\
\hline LEVEL 2 & 296 & 306 & 444 & 459 & 667 & 689 \\
\hline LEVEL 1 & 599 & 636 & 899 & 955 & 1348 & 1432 \\
\hline TERRACE & 1116 & 1206 & 1674 & 1809 & 2512 & 2714 \\
\hline NINTH & 1583 & 1551 & 2374 & 2327 & 3561 & 3491 \\
\hline EIGHTH & 1884 & 1711 & 2825 & 2566 & 4238 & 3849 \\
\hline SEVENTTH & 2139 & 1831 & 3209 & 2747 & 4813 & 4120 \\
\hline SIXTH & 2407 & 2005 & 3611 & 3008 & 5416 & 4512 \\
\hline FIFTH & 2669 & 2247 & 4003 & 3370 & 6005 & 5055 \\
\hline FOURTH & 2889 & 2538 & 4334 & 3806 & 6501 & 5710 \\
\hline THIRD & 3106 & 2845 & 4658 & 4267 & 6988 & 6401 \\
\hline SECOND & 3313 & 3064 & 4969 & 4596 & 7454 & 6895 \\
\hline FIRST & 3410 & 3310 & 5115 & 4965 & 7673 & 7448 \\
\hline
\end{tabular}

Table 5. Storey Shear in kN for all Zones considered as per IS 1893 (Part1): 2002

\section{Discussion of Results}

- During the Schematic stage, the lateral load resisting members are placed in a position by trial and error method, such that the overall mass of the building coincides with the rigidity of lateral load resisting member as far as possible to avoid the torsion in the building during initial modes.

- Base shear with infill is found to be $4288 \mathrm{kN}$ and without infill it is $2531 \mathrm{kN}$. Average of the both is taken for the design, considering the realistic condition.
- It is found that the first mode excites at $65.26 \%$ of the total mass in $Y$ direction and second mode excites at $67.71 \%$ of the total mass $X$ direction and both are in pure translation which is an acceptable solution to proceed with detailed design of structural elements.

- More than $90 \%$ of total mass participated by acceleration is within 10 modes and satisfies the clause 7.8.4.2 of IS 1893 (Part 1): 2002.

- Base shear in $X$ and $Y$ direction are found to be 3.15\% and $3.05 \%$ of total seismic weight of building respectively.

- Lateral drifts are found to be within the limits of 0.004 times the storey height as per clause 7.11.1 of IS 1893 (Part1): 2002.

- The seismic force attraction and the lateral displacements in $X$ and $Y$ directions are found to be reasonable with respect to the stiffness present in their respective direction.

- Force attracted by the moment resisting frames are $10.8 \%$ and $15.6 \%$ of shear in $X$ and $Y$ direction, where as these values are less than $25 \%$ of design seismic base shear as per Table 7 of IS 1893 (Part1): 2002. The columns are 
designed for 2.3 and 1.6 times more force than actual in $X$ and $\mathrm{Y}$ direction respectively to satisfy the Codal provisions.

- The same building is analyzed with other zone factors as per IS 1893 (Part1): 2002 and the results are compared. It is found that the base shear is increased in higher zones as per the ratio times the zone factors.

\section{Conclusion}

A Case Study of upcoming Ten Storey Hospital building falling in Zone III of IS 1893 (Part 2): 2002 has been carried out to illustrate the various seismic parameters governing the seismic forces on the building. The structure was modeled in modernized structural engineering software package ETABS. The earthquake ground acceleration is given as a digitized response-spectrum curve of pseudospectral acceleration response versus period of the structure. Dual systems are considered to resist the lateral force and the column forces are amplified to meet the requirements of codal provisions. Serviceability criteria such as storey drifts are within the limiting value as stated in the Codal provisions. Translation modes of displacements are occurred at the initial modes and more than $90 \%$ of masses are accelerated within first 10 modes. The presented approach enables engineers to arrive at a realistic solution for the seismic analysis of multi storey building and the influence of various seismic zone factors on structures.

\section{Nomenclature}

$A_{k} \quad$ - Design horizontal spectrum value using natural period of vibration Tk of mode $k$

$A_{h}$ - Design horizontal spectrum value using natural period for a structure

B - Frequency ratio $=\omega \mathrm{i} / \omega \mathrm{j}$

CQC - Complete Quadratic Combination

$E Q_{x}$ - Earthquake force in X direction in $\mathrm{kN}$

$E Q_{Y}$ - Earthquake force in $Y$ direction in $\mathrm{kN}$

I - Importance Factor

$M_{x}$ - Moment aboutX axis in kN.m

$M_{y}$ - Moment about Y axis in KN.m

$M_{k}$ - Modal mass

$\mathrm{P} \quad$ - Axial force in $\mathrm{kN}$

$P_{k} \quad$ - Modal Participation factor
Qi $\quad$ - Peak lateral force at floor i in modek

R - Ductility Factor

$\mathrm{Sa} / \mathrm{g}$ - Spectral acceleration coeffiecnt

SMRF - Special Moment Resisting System

SRSS - Square Root of Sum of Square

T - Torsion in kN.m

$\mathrm{T}_{\mathrm{a}} \quad$ - Fundamental natural period

$T_{k} \quad$ - Natural period of vibration of mode $k$

TOC - Top of concrete

$V_{B} \quad$ - Base shear calculated from dynamic analysis in $\mathrm{kN}$

$V_{\text {в }}$ - Base shear calculated using fundamental natural period Ta in $\mathrm{kN}$

$V_{i} \quad$ - The peak storey shear force in storey in $\mathrm{kN}$

$V_{i k} \quad$ - The peak shear force acting in storey i in mode $k$

$V_{x} \quad$ - Shear Force in X direction in kN

$V_{Y} \quad$ - Shear Force in Y direction in $\mathrm{kN}$

W - Seismic weight of structure in $\mathrm{kN}$

$\mathrm{W}_{\mathrm{i}}$ - Seismic weight of floor i in $\mathrm{kN}$

Z - ZoneFactor

$d_{x}$ - Base dimension in X direction in $m$

$d_{y}$ - Base dimension in Y direction in $m$

9 - Acceleration due to gravity

h - Height of the building in $m$

$r$ - Number of modes being considered,

$\varphi i_{k} \quad$ - Mode shape coefficient at floor in mode k

pij - Cross-modal coefficient

$\lambda \mathrm{i} \quad$ - Response quantity in mode i including sign

$\lambda j \quad$ - Response quantity in mode jincluding sign

$\zeta \quad-$ Modal damping ratio (in fraction) $2 \%$ and $5 \%$ for steel and reinforced concrete building respectively.

$\omega \mathrm{i} \quad$ - Circular frequency in ith mode and

$\omega j \quad$ - Circular frequency in jth mode

$\lambda_{k} \quad$ - Absolute value of quantity in mode $k$

$\lambda^{\star}$ - Peak response quantity due to the closely spaced modes 


\section{References}

[1]. Shahabodin.Zaregarizi (2008). Comparative Investigation on using Shear Wall and Infill to improve Seismic Performance of existing buildings, $14^{\text {th }}$ World Conference on Earthquake Engineering, October 12-17, Beijing, China.

[2]. Thomas Paulay (1983). Deterministic Seismic Design Procedures for reinforced Concrete Buildings, Engineering Structures, Vol. 5, No. 1, pp. 79-86.

[3]. Hyun-Su Kima, Dong-Guen Leea and Chee Kyeong Kimb (2005). Efficient three-dimensional seismic analysis of a high-rise building structure with shear walls,
Engineering Structures, Vol. 27, No. 6, pp. 963-976.

[4]. Shahram Taghavi and Eduardo Miranda (2008). Response Spectrum Method for Estimation of Peak Floor Acceleration Demand, $14^{\text {th }}$ World Conference on Earthquake Engineering, October 12-17, Beijing, China.

[5]. Moehle J.P and Mahin S.A (1991). Observations on the Behavior of Reinforced Concrete Building during Earthquakes, American Concrete Institute Publication SP127.

[6]. IS 1893-Part 1 (2002). Criteria for Earthquake Resistant Design of Structures (Fifth Revision), Bureau of Indian Standards, New Delhi - 110002.

\section{ABOUT THE AUTHORS}

* Professor \& Head, Department of Civil Engineering, Coimbatore Institute of Technology, Coimbatore.

** PhD candidate, Anna University of Technology, Coimbatore. 
Reproduced with permission of the copyright owner. Further reproduction prohibited without permission. 